\title{
PERBANDINGAN MODEL MALTHUS DAN MODEL VERHULST UNTUK ESTIMASI JUMLAH PENDUDUK INDONESIA TAHUN $2000-2014$
}

\author{
WIDYA PUTRI \\ Program Studi Matematika, \\ Fakultas Matematika dan Ilmu Pengetahuan Alam, Universitas Andalas, \\ Kampus UNAND Limau Manis Padang, Indonesia. \\ widyaputri848@gmail.com
}

\begin{abstract}
Abstrak. Penelitian ini bertujuan untuk menentukan model dan menghitung estimasi jumlah penduduk Indonesia tahun 2000 - 2014 berdasarkan jenis kelamin dan kelompok umur yang lebih mendekati dengan estimasi jumlah penduduk Indonesia yang dilakukan oleh BPS karena metode estimasi yang dilakukan oleh BPS Indonesia tersebut tidak diketahui. Penelitian ini menggunakan data sekunder dari Badan Pusat Statistika (BPS) Sumatera Barat. Model yang digunakan untuk estimasi jumlah penduduk Indonesia tahun 2000 - 2014 adalah model Malthus (model eksponensial) dan model Verhulst (model logistik). Dari kedua model dibandingkan dengan galat, yaitu galat terkecil sebagai model estimasi jumlah penduduk Indonesia yang lebih mendekati dengan hasil estimasi BPS. Hasil estimasi jumlah penduduk Indonesia dengan model Verhulst yang lebih mendekati dengan hasil estimasi BPS, sehingga dapat disusun ke dalam bentuk tabel dan dapat digambarkan ke dalam bentuk piramida penduduk untuk melihat komposisi penduduk dan distribusi penduduk berdasarkan kelompok umur.
\end{abstract}

Kata Kunci: Estimasi jumlah penduduk, model Malthus, model Verhulst

\section{Pendahuluan}

Persamaan diferensial dapat membentuk suatu model matematika yang diperoleh dari perumusan abstraksi sebagai permasalahan fenomena yang ada di alam dan di lingkungan kehidupan manusia sehari-hari. Model matematika dapat mencari penyelesaian dan memecahkan permasalahan dari berbagai bidang keilmuan dan salah satu nya adalah pada bidang demografi. Dalam kajian demografi, diantaranya terdapat dua model pertumbuhan penduduk yang digunakan dalam mengukur jumlah penduduk, yaitu model Malthus (model eksponensial) dan model Verhulst (model logistik).

Di Indonesia data jumlah penduduk yang paling mendekati kondisi sebenarnya hanyalah data hasil sensus penduduk yang dilaksanakan oleh Badan Pusat Statistik (BPS) Indonesia setiap dalam sepuluh tahun pada tahun yang berakhiran angka nol. Setiap tahunnya antara tahun sensus penduduk, BPS melakukan estimasi jumlah penduduk Indonesia dari tahun ke tahun berdasarkan jenis kelamin dan kelompok umur. Namun, metode atau model pertumbuhan penduduk untuk estimasi jumlah penduduk yang dilakukan BPS Indonesia tidak diketahui. Penulis tertarik meneliti model pertumbuhan penduduk yaitu model Malthus (model eksponensial) 
dan model Verhulst (model logistik) untuk estimasi jumlah penduduk Indonesia. Dari kedua model pertumbuhan penduduk itu ditentukan salah satu model pertumbuhan penduduk yang paling mendekati dengan data hasil estimasi jumlah penduduk Indonesia pertahun berdasarkan jenis kelamin dan kelompok umur pada tahun 2000 - 2014 yang dilakukan oleh BPS.

\section{Persamaan Diferensial dan Model Pertumbuhan Penduduk}

\subsection{Persamaan Diferensial}

Persamaan diferensial adalah persamaan yang memuat turunan satu (atau beberapa fungsi) yang tidak diketahui.

Definisi 2.1. [3] Suatu persamaan diferensial biasa orde $n$ adalah suatu persamaan yang dapat ditulis dalam bentuk

$$
y^{(n)}=F\left(x, y, y^{\prime}, \ldots, y^{(n-1)}\right)
$$

dimana $y, y^{\prime}, \ldots, y^{(n)}$ semua ditentukan nilainya oleh $x$.

Mencari penyelesaian persamaan diferensial dapat dilakukan dengan teknik persamaan diferensial dengan peubah terpisah dan persamaan diferensial dengan peubah yang dapat dipisahkan. Persamaan diferensial orde satu dapat dinyatakan dengan persamaan

$$
M(x, y) d x+N(x, y) d y=0 .
$$

Berdasarkan persamaan diferensial orde satu dengan peubah terpisah diperoleh penyelesaian umum

$$
\int f(x) d x+\int g(y) d y=c .
$$

Dari bentuk umum 2.1, dimisalkan $M(x, y)=f_{1}(x) g_{2}(y)$ dan $N(x, y)=$ $f_{2}(x) g_{1}(y)$, berdasarkan persamaan diferensial orde satu dengan peubah yang dapat dipisahkan diperoleh penyelesaian umum

$$
\int \frac{f_{1} x}{f_{2} x} d x+\int \frac{g_{1} y}{g_{2} y} d y=C .
$$

\subsection{Model Pertumbuhan Penduduk}

Tabel 1 dan 2 merupakan hasil sensus penduduk tahun 2000 dan 2010 dan hasil estimasi penduduk 2001 sampai 2009 serta 2011 sampai 2014 menurut kelompok umur interval 5 tahun dan jenis kelamin yang dilakukan oleh BPS Indonesia.

\section{Estimasi Jumlah Penduduk Indonesia dengan Model Malthus}

Model pertumbuhan penduduk Malthus dikenal dengan model eksponensial, dituliskan dalam bentuk

$$
\frac{d P}{d t}=\lambda P, \lambda>0
$$


Perbandingan Model Malthus dan Model Verhulst untuk Estimasi Penduduk 3

Tabel 1. Estimasi Jumlah Penduduk Laki-Laki Indonesia Tahun 2000-2014

\begin{tabular}{|c|c|c|c|c|c|c|c|c|}
\hline I Th & 2000 & 2001 & 20002 & $\mathbf{2 0 0 3}$ & 2004 & 2006 & 2006 & 2007 \\
\hline $0-4$ & 10_159_400 & 10264900 & 10294000 & 10.918.700 & 10344_000 & 10364400 & 10419900 & 10.459 .800 \\
\hline $5-9$ & 11117_100 & 10926700 & 10.750.400 & 10526000 & 10306200 & 10082900 & 10.134200 & 10180100 \\
\hline $10-14$ & 10.780 .600 & 10896300 & 10902800 & 10.961.400 & 12020700 & 11077890 & 10866.800 & 10.6698900 \\
\hline $15-19$ & 10609400 & 10628.800 & 10.655 .400 & 10.679 .100 & 10704.400 & 10.727900 & 10.780900 & 10840200 \\
\hline $20-24$ & 9722800 & $9887 \times 0$ & 10046200 & 10.298__100 & 10967300 & 10524900 & 10546200 & 10572100 \\
\hline $25-29$ & 9103900 & 9219300 & 9348000 & 9466900 & 9565200 & 9.61500 & gsangan & 9987900 \\
\hline so-34 & 8427800 & $8597, \pi 0$ & 8.729 300 & 8.828300 & 8920500 & 9.012500 & 9_151_400 & 9257900 \\
\hline 35-39 & 7512700 & 7.685900 & 7857900 & 8025900 & 8182100 & 8324800 & 8.455_000 & $85 \operatorname{seng} 90$ \\
\hline 40-44 & 6479500 & 6.6P5_600 & 6.865900 & 7049200 & 7216300 & 7387100 & 7556290 & 7.728200 \\
\hline $45-49$ & 5159500 & 5987290 & 5629000 & 5866.800 & 6.096000 & 6311.400 & 6507900 & 6.695900 \\
\hline $50-54$ & 3869200 & 4068_000 & $4.27 \mathrm{LgxO}$ & 4.492700 & 4.721000 & 4952000 & 5_185_. & 5.418 .890 \\
\hline $55-59$ & 2987100 & 3.002200 & $319 \times 100$ & 3326000 & 3.479_300 & 3_.655_700 & S_8X0_000 & 4021100 \\
\hline $60-64$ & 2474400 & 246B_400 & 2.499 .400 & 2558.200 & 2693900 & 2712300 & 2801290 & 2910300 \\
\hline $65-69$ & 1805700 & L855_690 & 1909600 & 1969.600 & 20097600 & 2180600 & 2160_ado & 2190600 \\
\hline $70-74$ & 1264800 & 1235_100 & $1297 \_100$ & 1272100 & 1997100 & 1_4s0000 & L489_100 & $155 \mathrm{R} .100$ \\
\hline $75+$ & 1966500 & 1988_a00 & 1.412000 & 1.499000 & 1.467 .000 & 1_497_700 & 1592000 & 1568.000 \\
\hline Totil & 102822.400 & 104_196000 & $105-584.900$ & 106982000 & 108992000 & 109801.700 & 111208500 & $112.62 J_{-100}$ \\
\hline
\end{tabular}

\begin{tabular}{|c|c|c|c|c|c|c|c|}
\hline Tithun & 2008 & 2009 & 2010 & 2011 & 2012 & 2013 & 2014 \\
\hline $0-4$ & $10 \_490 \_100$ & $10 \_523 \_100$ & 10567200 & $10 \_590 \_500$ & $10 \_613.400$ & 10.640 .100 & 10_663_700 \\
\hline $5-9$ & 10.220 .400 & $10 \_270 \_400$ & 10311 -400 & $10357-800$ & $10 \_402700$ & 10.446 .400 & 10_488_000 \\
\hline $10-14$ & 10.458 .000 & 10255200 & 10056200 & 10_100_400 & $10 \_149300$ & 10_195_000 & 10243500 \\
\hline $15-19$ & 10.904500 & 10.964500 & 11036 & 10.828 .700 & $10 \_627.800$ & 10.425500 & 102224,000 \\
\hline $20-24$ & 10598.400 & 10.627200 & 10656 .800 & 10.718 .900 & 10_781500 & 10.8502200 & $10 \$ 12900$ \\
\hline 25-29 & $10 \_175200$ & 103362200 & 10_443_800 & 10.482 .600 & $10 \_27500$ & 10562200 & $10 \_577.800$ \\
\hline $30-34$ & 9341500 & 9.432 .600 & 9554.900 & 9.757000 & 9.938 .900 & 10 111600 & $10 \_260300$ \\
\hline $35-39$ & 8_702_100 & 8.814100 & 8.925_000 & 9.026600 & 9_124_400 & 9224 & 9339_700 \\
\hline $40-44$ & $7.897-400$ & 8.059_400 & 82211600 & 8.346 .900 & 8_475_700 & 85972200 & 8_708_900 \\
\hline $45-49$ & 6.874 .000 & 7.051000 & 7230000 & 7.401 700 & 7571.400 & 7.744_800 & 7008.500 \\
\hline $50-54$ & 5651900 & 5.879 .900 & 6_098_000 & 6.297600 & 6.482300 & 6.658 600 & 6.836 .300 \\
\hline 55-59 & 4236200 & 4.461100 & 4_685_100 & 4911900 & $5 \_142400$ & $5370 \_800$ & 5590.600 \\
\hline $60-64$ & $3032 \_400$ & 3.172300 & 3328.600 & 3504200 & 3_695_500 & 3.898_700 & 4_109_700 \\
\hline $65-69$ & 22201700 & 2284600 & 2360.700 & 2442600 & 2537.800 & 2645900 & 2780900 \\
\hline $70-74$ & 1623200 & 1.676100 & 1.710 .400 & 1.767100 & 1.812200 & 1.848300 & 1.8855300 \\
\hline $75+$ & 1607 100 & 1.651000 & 1_699_100 & 1.753.000 & 1.816_100 & 1.881200 & 1.956 .200 \\
\hline Totril & 114_0s1_100 & 115_458_700 & 116.875 .800 & 118287500 & 119698 900 & 121_100_500 & 122,486300 \\
\hline
\end{tabular}

dimana $\lambda$ menyatakan laju pertumbuhan penduduk. Berikut ini adalah solusi jum-

lah penduduk $P$ pada saat $t$ atau $P_{t}$ berdasarkan (3.1), diperoleh

$$
\begin{gathered}
\frac{d P}{P}=\lambda d t \\
\frac{1}{P} d P=\lambda d t \\
\int_{P_{0}}^{P_{t}} \frac{1}{P} d P=\int_{0}^{t} \lambda d t \\
P_{t}=P_{0} e^{\lambda t}
\end{gathered}
$$


Tabel 2. Estimasi Jumlah Penduduk Perempuan Indonesia Tahun 2000-2014

\begin{tabular}{|c|c|c|c|c|c|c|c|c|c|c|c|}
\hline & 2000 & \multicolumn{2}{|c|}{2001} & \multicolumn{2}{|c|}{2002} & 20003 & 2004 & 2005 & 20096 & \multicolumn{2}{|c|}{2007} \\
\hline $0-4$ & 9.798600 & \multicolumn{2}{|c|}{ 9844000 } & \multicolumn{2}{|c|}{ 9.886_700 } & 9921_700 & 9954000 & 9985_100 & 10021_490 & \multicolumn{2}{|c|}{10055 100 } \\
\hline $5-9$ & 10.749300 & \multicolumn{2}{|c|}{10.563300} & \multicolumn{2}{|c|}{10368.800} & 10.166.dAd & 9960300 & 9_747_800 & 9.792.800 & \multicolumn{2}{|c|}{9.830500} \\
\hline 10-14 & 10370_.0A9 & \multicolumn{2}{|c|}{ 10_449_(XXO } & \multicolumn{2}{|c|}{10524500} & 10593 690 & 10.660_909 & 10.724000 & 10525 490 & \multicolumn{2}{|c|}{ 10325_100 } \\
\hline $15-19$ & 10567900 & \multicolumn{2}{|c|}{10529500} & \multicolumn{2}{|c|}{10.485300} & 104438_460 & 10389500 & 10337460 & 10408_200 & \multicolumn{2}{|c|}{ 10.478.700 } \\
\hline $20-24$ & \multirow{2}{*}{$\frac{10295 \_100}{9563.900}$} & 10 & 46.400 & 10399 & 900 & 10.4359 & 10_480_400 & 10517200 & 10A73_800 & & 127.600 \\
\hline $25-29$ & & 9.7 & 9100 & 9.882 & 700 & 100357 & 10.157200 & 10230900 & 10285.690 & & 348300 \\
\hline 30-34 & 8.479.400 & 8.7 & 1500 & 8969 & 180 & 9.15620 & 9325600 & 9_489_00 & 9.693 1000 & & 47.700 \\
\hline $35-39$ & 7.430000 & 76 & 3100 & 7.873 & 6X0 & 8.02080 & 8204100 & 8395200 & 8598.600 & & 09200 \\
\hline $40-44$ & 6.123 800 & 63 & 8300 & 6.644 & AdO & $6.888 \mathrm{A0}$ & 7114460 & 7330.600 & 7536900 & & 29.490 \\
\hline $45-49$ & 4.675 .800 & 49 & 3000 & 5.188 & $8 \mathrm{AO}$ & 5,466 8 7 & 5.741100 & 6.097_100 & 6264_700 & & 15 180 \\
\hline $50-54$ & 3.615500 & & 0900 & 3939 & 703 & 4.11960 & 4319900 & 4543_200 & 4785600 & & 46909 \\
\hline $55-59$ & 2933800 & & 8.200 & 3.698 & QAO3 & 3208.00 & 3330200 & 3_463_8d0 & 3.616900 & & 78.200 \\
\hline $60-64$ & 2585600 & & 1.460 & 2599 & 200 & 263820 & 2689300 & $2747 \_100$ & 2817200 & & 08300 \\
\hline $65-69$ & 2007100 & & 67.700 & 2129 & 6A0 & 218650 & 2247600 & 2324_000 & 2344500 & & 62.690 \\
\hline $70-74$ & 1389300 & & 0.100 & 1.432 & 100 & 1.49110 & 1576100 & 1.6802000 & 1.747100 & & 23_100 \\
\hline $75+$ & 1.724500 & & 60000 & $1 . T 72$ & ado & 1.892 .00 & 1839000 & 1.879900 & 1932 900 & & 92000 \\
\hline Toty & 102309600 & 103. & 31500 & 10525 & 2000 & 1065685 & \begin{tabular}{|l|l|}
00 & $107989 \_600$ \\
\end{tabular} & 109_403_dxo & 110.842 .800 & & $2 T 7800$ \\
\hline Umir & 2008 & & & & & 2010 & 2011 & 2012 & 2013 & & 2014 \\
\hline $0-4$ & 10.092 & $\mathbf{0 0 0}$ & $10 \_12$ & 9200 & 10 & 160.500 & $10 \_180 \_800$ & 10202300 & 102229 & & 10243900 \\
\hline $5-9$ & 9.8712 & & 991 & 500 & 99 & 49200 & 9.989 .100 & 10.028600 & 10_067_2 & & $10 \_102200$ \\
\hline $10-14$ & 10.125 & 00 & 992 & 100 & 97 & 32900 & $9-771800$ & 9.813200 & 9.8578 & & $9.896 \_800$ \\
\hline $15-19$ & 1055 & 0 & 10 & 00 & 10 & 200 & 10505200 & 8700 & 10 & & 100 \\
\hline $20-24$ & 10384 & 100 & 1034 & 600 & 10 & 301400 & 10375300 & 10.449600 & 10525 & & 2300 \\
\hline $25-29$ & 10.405 & 100 & 10.44 & 5300 & 10 & 469700 & 10.429200 & 10385500 & 103391 & & 10298 .100 \\
\hline $30-34$ & 9.970 .6 & $\mathbf{0 0}$ & 10.07 & 5.600 & 10. & 172600 & $10 \_263$.400 & 10334800 & 103885 & & 10.422500 \\
\hline $35-39$ & 9.0242 & $\mathbf{0 0}$ & 922 & 200 & 9.4 & 17500 & 9.588 .900 & 9.744 .400 & 9.88610 & & 10_008_000 \\
\hline $40-44$ & 7.915 & & 8_10 & 500 & & $05 \_600$ & 8.510 .200 & 8_721_700 & 893920 & & 9.1452200 \\
\hline $45-49$ & 6756 & & 69 & 200 & & 14200 & 7.420 .000 & 7.613 .400 & 7.80070 & & 7992.700 \\
\hline $50-54$ & 5.320 & & 559 & 000 & & 61.700 & 6.118 .800 & 6369200 & 660950 & & 6.8386000 \\
\hline $55-59$ & 3.9581 & & 4.15 & 200 & & 76300 & 4.613 .100 & 4.871 .400 & 5.14160 & & 5.410 .700 \\
\hline $60-64$ & 3_014_4 & 00 & 3.13 & 300 & 32 & 66.400 & 3_413_300 & 3571500 & 374670 & & $3939 \_800$ \\
\hline $65-69$ & 2390.7 & 00 & 2.43 & 600 & 24 & 93500 & $2564 \_600$ & $26550 \_800$ & 274990 & & 2863900 \\
\hline $70-74$ & 1890.2 & & 194 & 100 & & 711000 & 2014 & 2044200 & 207030 & & 2.103300 \\
\hline $75+$ & 2057.1 & & 2.13 & 000 & & 06900 & 2286.000 & 2366.100 & 245430 & & 2546200 \\
\hline Total & 113.728 & 000 & 115_1 & 4.000 & 116 & $601 \_600$ & 118_043_800 & $119-475,400$ & 1209133 & & 122328600 \\
\hline
\end{tabular}

Sumber: BPS [2]

$$
\lambda=\frac{1}{t} \ln \frac{P_{t}}{P_{0}}
$$

Dalam Tabel 3 disajikan hasil estimasi jumlah penduduk Indonesia tahun 2000 - 2014 berdasarkan jenis kelamin dan kelompok umur dengan menggunakan Model Malthus.

Dengan mengabaikan faktor selisih imigrasi dan emigrasi, maka seharusnya jumlah penduduk semakin berkurang karena ada sejumlah penduduk yang mati. Hal ini terjadi karena setiap kelompok umur itu memiliki peluang hidup yang sama. Namun, secara keseluruhan untuk jumlah estimasi penduduk baik laki-laki maupun perempuan (dengan mengabaikan kelompok umur) masih bisa diterima. Kesalahan yang sama juga terjadi pada estimasi jumlah penduduk dengan menggunakan model Verhulst bila dibagi dalam kelompok-kelompok umur. 
Tabel 3. Estimasi Jumlah Penduduk Indonesia Berdasarkan Jenis Kelamin dan Kelompok Umur dengan Model Malthus

\begin{tabular}{|c|c|c|c|c|c|c|}
\hline \multirow[t]{2}{*}{ Keilompoik Unirs } & \multicolumn{2}{|l|}{2000} & \multicolumn{2}{|l|}{2001} & \multicolumn{2}{|l|}{2002} \\
\hline & Lalki-1aki & Peremponan & Lalki-1aki & Peremponan & Lalki-1aki & Peremppuan \\
\hline $0-4$ & 10.153 .400 & 9.798 .600 & 10.112 .922 & 9.834202 & 10.072 .605 & 9.869 .934 \\
\hline 5-9 & 11.117 .100 & 10.749300 & 11.033 .775 & 10.006 .477 & 10.951 .075 & 10.584 .291 \\
\hline $10-14$ & 10.780 .600 & 10.370 .000 & 10.705 .872 & 10.304 .457 & 10.631 .661 & 10.239328 \\
\hline $15-19$ & 10.609 .400 & 10.567500 & 10.051 .317 & 10.581 .254 & 10.093399 & 10.594 .624 \\
\hline $20-24$ & 9.722 .800 & 10.295 .100 & 9.812 .392 & 10.295 .730 & 9902.810 & 10.296360 \\
\hline $25-29$ & 9.103 .900 & 9563.900 & 9.229 .704 & 9.650 .836 & 9357.308 & 9.738 .563 \\
\hline $30-34$ & 8.427 .800 & 8.479 .400 & 8.534 .251 & 8.635 .188 & 8.042 .047 & 8.793 .839 \\
\hline $35-39$ & 7512.700 & 7.430 .000 & 7.643 .236 & 7.608228 & 7.776 .040 & 7.790 .730 \\
\hline $40-44$ & 6.473 .500 & 6.123 .800 & 6.629 .305 & 6.313294 & 6.788 .860 & 6508.651 \\
\hline $45-49$ & 5.153 .500 & 4.675 .800 & 5.331 .032 & 4.883 .027 & 5514.680 & 5.099 .439 \\
\hline $50-54$ & 3.869 .200 & 3.615 .500 & 4.049 .280 & 3.794 .494 & 4237.741 & 3982.350 \\
\hline $55-59$ & 2987.100 & 2933.800 & 3.124 .616 & 3.053502 & 3208.403 & 3.178 .087 \\
\hline $60-64$ & 2.474 .400 & 2585.600 & 2.548 .878 & 2.046 .745 & 2.625 .598 & 2.709 .336 \\
\hline $65-\infty$ & 1.805 .700 & 2.007 .100 & 1.854 .749 & 2.051 .129 & 1905.130 & 2.096 .125 \\
\hline $70-74$ & 1264.800 & 1389.300 & 1.303 .555 & 1.438 .749 & 1343.498 & 1.489 .958 \\
\hline $75+$ & & 1.2 & 2.929 .154 & 1.767564 & 2.626 .804 & 1.811 .703 \\
\hline & .822 & 500 & 38 & . & & $104.2+3$ \\
\hline
\end{tabular}

\begin{tabular}{|c|c|c|c|c|c|c|}
\hline \multirow[t]{2}{*}{ Ketompok Unmax } & \multicolumn{2}{|l|}{2003} & \multicolumn{2}{|l|}{2004} & \multicolumn{2}{|l|}{2005} \\
\hline & Laki-laki & Peremplan & Laki-laki & Perempunan & Laki-1ziki & Perempuan \\
\hline $0-4$ & 10.032 .449 & 9.905 .795 & 9.092 .453 & 9941.787 & 9.952 .617 & 9.977 .909 \\
\hline $5-9$ & 10.808 .994 & 10502.739 & 10.787 .529 & 10.421 .815 & 10.706 .674 & 10.341 .515 \\
\hline $10-14$ & 10557.965 & 10.174 .611 & 10.484 .780 & 10.110 .303 & 10.412 .102 & 10.0 \\
\hline $15-19$ & 10.735 .048 & 10.608 .012 & 10.778 .064 & 10.621 .417 & 10.820 .647 & 10.634 .838 \\
\hline $20-24$ & 9.994 .061 & 10296990 & 10.086 .153 & 10.207 .620 & 10.179 .093 & 10.298 .250 \\
\hline $25-20$ & 9.486 .736 & 9.827 .087 & 9.617 .892 & 9916.415 & 9.750 .862 & 10.0066556 \\
\hline $30-34$ & 8.751204 & 8.055 .404 & 8.861 .740 & 0.110 .937 & 8.973 .672 & 9.287 .494 \\
\hline $35-39$ & 7.911 .151 & 7.977 .611 & 8.048 .611 & 8.168 .974 & 8.188 .458 & 8.364.928 \\
\hline $40-44$ & 0.952256 & 0.710 .054 & 7.119584 & 0.917 .089 & 7.200 .939 & 7.131 .748 \\
\hline $45-49$ & 5.704 .654 & 5.325 .441 & 5.901 .173 & 5561.460 & 6.104 .461 & 5.807 .939 \\
\hline so-54 & 4.434974 & 4.179 .500 & 4.04 & 4386.422 & 4.857 .405 & 4.003 .583 \\
\hline $55-59$ & 3.418932 & 3.307 .756 & 3.576328 & 3.442 .716 & 3.740 .971 & 3.583 .181 \\
\hline $60-64$ & 2.704 .627 & 2.773 .408 & 2.786 .035 & 2.838.994 & 2.809 .893 & 2.906 .132 \\
\hline $65-69$ & 1.956 .880 & 2.142 .107 & 2.010 .035 & 2.189 .098 & 2.064 .635 & 2.237 .120 \\
\hline $70-74$ & 1.384 .665 & 1.542 .9090 & 1.427 .093 & 1597.910 & 1.470 .821 & 1.654 .784 \\
\hline $75+$ & 2.35 & & 2.1 & 1903.316 & & 1.950 .846 \\
\hline Tota & 107.250 .965 & 106.086 .450 & 108.231 .508 & 107.435 .873 & 109277.876 & 108.833 .2 \\
\hline
\end{tabular}

\begin{tabular}{|c|c|c|c|c|c|c|}
\hline \multirow[t]{2}{*}{ Kelompolk Unmer } & \multicolumn{2}{|l|}{20006} & \multicolumn{2}{|l|}{20007} & \multicolumn{2}{|l|}{2008} \\
\hline & Lakiki-laki & Penempanan & Lakīi-lakiki & Perempanan & Lakílakiki & Perempuan \\
\hline 04 & 9912939 & 10.014 .163 & 9.873 .420 & 10.050 .549 & 9.834 .058 & 10.087 .066 \\
\hline $5-9$ & 10.626 .425 & 10.261 .834 & 10.546 .778 & 10.182 .766 & 10.467 .728 & 10.104 .308 \\
\hline $10-14$ & 10.339 .928 & 9982903 & 10.268 .254 & 9.919 .807 & 10.197 .077 & 9.857 .109 \\
\hline $15-19$ & 10.863 .398 & 10.648 .276 & 10.906 .319 & 10.661 .732 & 10.949 .409 & 10.675 .204 \\
\hline $20-24$ & 10.272 .890 & 10.298 .880 & 10.367 .551 & 10.209 .510 & 10.463 .084 & 10.300 .140 \\
\hline $25-29$ & 9.885 .670 & 10.097 .516 & 10.022 .342 & 10.189 .303 & 10.160904 & 10.281 .924 \\
\hline $30-34$ & 9.087 .018 & 9.458 .120 & 9.201 .795 & 9.631 .899 & 9.318 .023 & 9.808 .861 \\
\hline $35-39$ & 8330.736 & 8565583 & 8.475 .485 & 8.771 .050 & 8.622 .750 & 8.981 .446 \\
\hline $40-44$ & 7.466 .419 & 7352.432 & 7.646 .122 & 7.579 .944 & 7.830 .150 & 7.814 .497 \\
\hline $45-49$ & 6314.752 & 6.065342 & 6.532 .288 & 6.334 .152 & 6.757 .318 & 6.614 .876 \\
\hline $50-54$ & 5.083 .478 & 4.831 .495 & 5.320 .072 & 5.070 .000 & 5.567 .679 & 5.321 .726 \\
\hline $55-59$ & 3913.193 & 3.720378 & 4.093 .343 & 3.881 .540 & 4.281 .787 & 4.039 .911 \\
\hline $60-64$ & 2956276 & 2974.857 & 3.045 .258 & 3.045 .208 & 3.136 .919 & 3.117 .222 \\
\hline $65-69$ & 2.120 .717 & 2286.195 & 2.178 .323 & 2.336 .347 & 2.237 .493 & 699 \\
\hline $70-74$ & 1515.889 & 1.713 .683 & 1.562 .338 & 1.774 .678 & 1.610 .210 & 1.837 .843 \\
\hline $75+$ & 1.853 .799 & 1999562 & 1.813 .852 & 049.495 & 1.774 .765 & 2.100 .674 \\
\hline IDotn! & & 280 & 853 & 1.778 & 113.209 .352 & 113.330 .407 \\
\hline
\end{tabular}

\section{Estimasi Jumlah Penduduk Indonesia dengan Model Verhulst}

Pada tahun 1840 seorang matematikawan dan juga seorang ahli biologi berkebangsaan Belgia yaitu Pierre Verhulst yang mengubah model Malthus. Verhulst 
Tabel 4. Estimasi Jumlah Penduduk Indonesia Berdasarkan Jenis Kelamin dan Kelompok Umur dengan Model Malthus (lanjutan)

\begin{tabular}{|c|c|c|c|c|c|c|}
\hline \multirow[t]{2}{*}{ Kelompack Urmar } & \multicolumn{2}{|l|}{2009} & \multicolumn{2}{|l|}{2010} & \multicolumn{2}{|l|}{2011} \\
\hline & Lalci-lakici & Perempinan & Laki-1aki & Perempinan & Lalci-1aki & Perempuan \\
\hline $0-4$ & 9.794 .853 & 10.123 .717 & 9.755 .804 & 10.160 .500 & 9.716 .911 & 10.197 .417 \\
\hline 5-9 & 10.389 .270 & 10.026 .454 & 10311.400 & 9.949 .200 & 10234.114 & 9.872 .541 \\
\hline $10-14$ & 10.126 .394 & 9.794 .808 & 10.056200 & 9.732 .900 & 9.986 .493 & 9.671 .384 \\
\hline $15-19$ & 10.992 .669 & 10.688 .694 & 11.036 .100 & 10.702 .200 & 11.079 .703 & 10.715 .724 \\
\hline $20-24$ & 10.559 .498 & 10.300 .770 & 10.656 .800 & 10.301 .400 & 10.754999 & 10.302 .030 \\
\hline $25-29$ & 10.301 .381 & 10.375 .387 & 10.443 .800 & 10.469 .700 & 10588.188 & 10.564 .870 \\
\hline $30-34$ & 9.435 .718 & 9.989 .075 & 9.554 .900 & 10.172 .600 & 9.675 .587 & 10.359 .497 \\
\hline $35-39$ & 8.772.573 & 9.196 .889 & 8.925 .000 & 9.417 .500 & 9.080 .075 & 9.643 .403 \\
\hline $40-44$ & 8.018 .607 & 8.056 .307 & 8.211 .600 & 8.305 .600 & 8.409 .238 & 8.562.607 \\
\hline $45-49$ & 6.990 .099 & 6.908 .042 & 7.230 .900 & 7.214 .200 & 7.479 .996 & 7.533 .927 \\
\hline $50-54$ & 5.826 .809 & 5.585 .191 & 6.098 .000 & 5.861 .700 & 6.381 .813 & 6.151 .898 \\
\hline $55-59$ & 4.478 .906 & 4.204 .743 & 4.685 .100 & 4.376 .300 & 4.900 .786 & 4.554 .857 \\
\hline $60-64$ & 3.231 .338 & 3.190 .939 & 3.328 .600 & 3.266 .400 & 3.428 .789 & 3.343 .645 \\
\hline $65-69$ & 2.298 .271 & 2.439 .975 & 2.360 .700 & 2.493 .500 & 2.424 .825 & 2.548 .199 \\
\hline $70-74$ & 1.659 .549 & 1.903 .258 & 1.710 .400 & 1.971 .000 & 1.762 .809 & 2.041 .154 \\
\hline $75+$ & 1.736 .520 & 2.153.132 & 1.699 .100 & 2.206 .900 & 1.662 .486 & 2.262.010 \\
\hline Total & 114.612 .456 & 114937380 & 116.064 .404 & 116.601 .600 & 117.566 .81 & 162 \\
\hline
\end{tabular}

\begin{tabular}{|c|c|c|c|c|c|c|}
\hline \multirow[t]{2}{*}{ Kekompoik Umarr } & \multicolumn{2}{|l|}{2012} & \multicolumn{2}{|l|}{2013} & \multicolumn{2}{|l|}{2014} \\
\hline & L-aki-kikiki & Penemponan & Lalki-lakiki & Peremponan & Laiki-lnki & Perempuan \\
\hline $0-4$ & 9.678 .173 & 10.234 .468 & 9.639 .580 & 10.271 .654 & 9.001 .100 & 10.308 .975 \\
\hline $5=0$ & 10.157 .407 & 9.7906 .473 & 10.081 .275 & 9.720 .991 & 10.005 .714 & 9.645 .091 \\
\hline $10-14$ & 9917209 & 9.610256 & 0.848 .525 & 0.549 .515 & 9.780 .258 & 9.480 .158 \\
\hline $15-19$ & 11.123 .478 & 10.7229 .264 & 11.167 .426 & 10.742 .822 & 11.211547 & 10.756 .397 \\
\hline $20-24$ & 10.854 .102 & 10.302 .600 & 10.954 .119 & 10.303 .291 & 11.055 .057 & 10.303 .921 \\
\hline $25-29$ & 10.734 .573 & 10.000 .905 & 10.882 .981 & 10.757 .813 & 11.033 .441 & 10.855 .602 \\
\hline $30-34$ & 9.797 .799 & 10.549 .827 & 9.921 .555 & 10.743 .654 & 10.046 .873 & 10.941 .043 \\
\hline $35-39$ & 9237.845 & 9.874 .725 & 9.398 .356 & 10.111 .595 & 9.501 .050 & 10.354 .148 \\
\hline $40-44$ & 8.611 .633 & 8.827567 & 8.818.899 & 9.100 .726 & 9.031 .154 & 9.382 .337 \\
\hline $45-49$ & 7.737 .673 & 7.867 .824 & 8.004 .227 & $\mathbf{8 . 2 1 6 . 5 1 9}$ & 8.279. 903 & 8.580 .658 \\
\hline $50-54$ & 0.678 .834 & 0.456 .402 & 6.989 .680 & 0.776 .105 & 7.314 .993 & 7.111 .573 \\
\hline $55-59$ & 5.126 .402 & 4.740 .099 & 5.302 .405 & 4.934 .124 & 5.009 .272 & 5.135 .441 \\
\hline $60-64$ & 35315994 & 3.422 .717 & 3.638 .305 & 3.503 .059 & 3.747 .816 & 3.5886 .514 \\
\hline $05-00$ & 2.490 .091 & 2.604 .099 & 2.558 .346 & 2.001 .224 & 2.027 .840 & 2.719 .603 \\
\hline $70-74$ & 1.816 .824 & 2.113 .804 & 1.872 .494 & 2.189 .041 & $1.92 \times 9.870$ & 2.265 .955 \\
\hline $75+$ & 1.026 .001 & 2318.497 & 1.591 .008 & 2.376 .394 & 1.557 .311 & 2.435 .737 \\
\hline Tots & (2) & 120.110 & (2) & 121.959 & 393.923 & 123.874 .162 \\
\hline
\end{tabular}

mengusulkan sebuah model baru yang dikenal dengan model diferensial logistik, yaitu :

$$
\begin{aligned}
\frac{d P}{d t} & =\lambda P\left(1-\frac{P}{M}\right) \\
\int_{P_{0}}^{P_{t}} \frac{d P}{P\left(1-\frac{P}{M}\right)} & =\int_{0}^{t} \lambda d t \\
\frac{P_{t}\left(M-P_{0}\right)}{P_{0}\left(M-P_{t}\right)} d P & =\lambda t \\
P_{t} & =\frac{M}{e^{-\lambda t}\left(\frac{M}{P_{0}}-1\right)+1} \\
\lambda & =-\frac{1}{t}\left(\ln \frac{\left(\frac{M}{P_{t}}-1\right)}{\left(\frac{M}{P_{0}}-1\right)}\right)
\end{aligned}
$$


Perbandingan Model Malthus dan Model Verhulst untuk Estimasi Penduduk 7

Dalam Tabel 5 disajikan hasil estimasi jumlah penduduk Indonesia tahun 2000 - 2014 berdasarkan jenis kelamin dan kelompok umur dengan menggunakan Model Verhulst.

Tabel 5. Estimasi Jumlah Penduduk Indonesia Berdasarkan Jenis Kelamin dan Kelompok Umur dengan Model Verhulst

\begin{tabular}{|c|c|c|c|c|c|c|}
\hline \multirow[t]{2}{*}{ Kelompole Umm } & \multicolumn{2}{|l|}{2000} & \multicolumn{2}{|l|}{2001} & \multicolumn{2}{|l|}{2002} \\
\hline & Laki-1gli & Perempnan & Loli-1sin & Peremponan & L.glin-1gin & Perempanan \\
\hline $0-4$ & 10_153_400 & 9.798_600 & 10_194_042 & 9.834203 & 10234.846 & 9.869936 \\
\hline $5-9$ & 11_117_100 & 10.749300 & 11_033_781 & 10_666_482 & 10951 085 & 10,584301 \\
\hline $10-14$ & 10.780 .600 & 10370.000 & $10.705 \_876$ & 10304.461 & 10.631 .670 & 10239335 \\
\hline 15-19 & 10.609 .400 & 10567900 & 10.651 .318 & 10581254 & $10 \_693 \_402$ & 10.594 .625 \\
\hline $20-24$ & 9.722 .800 & 10295 _100 & 9.812 .399 & 10295.730 & 9902823 & 10296360 \\
\hline $25-29$ & 9.103900 & 9563900 & 9229.778 & 9.650 .843 & 9357394 & 9.738 .575 \\
\hline $30-34$ & 8.427 .800 & 8_479_400 & $8 \_534 \_261$ & 8.635211 & 8.642 .065 & 8.793_880 \\
\hline $35-39$ & 7512.700 & 7_430_000 & $7.643 \_252$ & 7.608258 & 7.776_.069 & 7.790 .786 \\
\hline $40-44$ & $6.473 \_500$ & 6_123_800 & 6.629 .328 & 6313329 & 6.788903 & 6508.716 \\
\hline $45-49$ & $5 \_1535500$ & 4.675_800 & 5331.063 & 4.883_071 & 55514.738 & 5.0995522 \\
\hline $50-54$ & 3.869200 & 3.615500 & 4.049.314 & 3.794528 & 4.237.805 & 3982.414 \\
\hline $55-59$ & 2987.100 & 2.933 .800 & 3_124_636 & 3_053516 & 3268500 & 3_178_115 \\
\hline $60-64$ & 2.474 .400 & 2585.600 & 2.548 .884 & 2.646 .749 & $2.625 \_608$ & 2.709343 \\
\hline $65-69$ & 1.805 .700 & 2.007 .100 & 1.854 .751 & 2051.131 & $1905 \_134$ & 2.096 .128 \\
\hline $70-74$ & 1264.800 & 1389300 & $1303 \_557$ & 1.438.752 & 1343501 & 1.489963 \\
\hline $75+$ & 1366500 & 1.724500 & $1396 \_596$ & 1.767566 & 1.427355 & 1.811 .707 \\
\hline Totsel & 102.822 .400 & 102309.600 & 104_042_.837 & 103 525_084 & 105300.897 & 104_783_704 \\
\hline
\end{tabular}

\begin{tabular}{|c|c|c|c|c|c|c|}
\hline \multirow[t]{2}{*}{ Kelompole Umur } & \multicolumn{2}{|l|}{2003} & \multicolumn{2}{|l|}{2004} & \multicolumn{2}{|l|}{2005} \\
\hline & Lski-1ski & Perempuan & Laki-1ski & Perempan & Lalai-1aini & Perempuan \\
\hline $0-4$ & 10275.813 & $9905 \_798$ & 10316943 & 9941.790 & 10358238 & 9977913 \\
\hline $5-9$ & 10_869_007 & 10.502752 & 10.787544 & 10_421_830 & 10.706 .690 & 10341531 \\
\hline 10-14 & $10 \_57976$ & 10_174.619 & $10 \_484.792$ & 10.110312 & 10.412115 & 10_046_411 \\
\hline $15-19$ & 10.735 .652 & 10_608_012 & 10_778_068 & 10.621 .417 & 10.820 .651 & 10.634 .838 \\
\hline $20-24$ & 9994_078 & 10296990 & $10 \_086.173$ & $10 \_297.620$ & 10_179_114 & 10298250 \\
\hline $25-29$ & 9.486.771 & 9.827_103 & 9.617933 & $9916 \_434$ & 9.750906 & $10 \_006576$ \\
\hline $30-34$ & 8.7512229 & $8955 \_459$ & 8.861.769 & 9_120_003 & 8.973_703 & 9287563 \\
\hline $35-39$ & 7911190 & $7977 \_686$ & 8_048_656 & 8_169_063 & 8_188_506 & $8365 \_024$ \\
\hline $40-44$ & 6952313 & 6.710 .143 & 7.119 .652 & 6917.794 & 7291_012 & 7.131.863 \\
\hline $45-49$ & 5.704_734 & 5325557 & 5901268 & 55561600 & 6.1045655 & 5_808_094 \\
\hline $50-54$ & 4.435_062 & 4.179_595 & 4.641_493 & 4.386531 & 4.857524 & 4.603_704 \\
\hline $55-59$ & 3.418 .984 & $3307-794$ & 3_5763991 & 3.442 .761 & 3.741_040 & 35832231 \\
\hline $60-64$ & 2704.641 & $2.773 \_417$ & 2786.051 & 2.839_005 & 2869911 & 2906143 \\
\hline $65-69$ & 1956.886 & 2142111 & $2010 \_042$ & 2189_103 & 2064.642 & 2237.125 \\
\hline $70-74$ & 1384.668 & 1542.997 & 1_427_097 & 1597917 & 1.470 .826 & 1.654 .792 \\
\hline $75+$ & 1.458 .791 & 1.856949 & 1.490919 & 1903322 & 1523.755 & 1950.851 \\
\hline Total & $106 \_597 / 795$ & $106 \_086983$ & $107 \_934 \_792$ & 107,436503 & 109_313_196 & 108_833_909 \\
\hline
\end{tabular}


Tabel 6. Estimasi Jumlah Penduduk Indonesia Berdasarkan Jenis Kelamin dan Kelompok Umur dengan Model Verhulst (lanjutan)

\begin{tabular}{|c|c|c|c|c|c|c|}
\hline \multirow[t]{2}{*}{ Kelompole Ummx } & \multicolumn{2}{|l|}{2006} & \multicolumn{2}{|l|}{2007} & \multicolumn{2}{|l|}{2008} \\
\hline & Laki-1alai & Perempanan & Laki-1aki & Perempnan & Laki-1aki & Perempuan \\
\hline $0-4$ & 10399.698 & $10 \_014 \_166$ & $10 \_441.323$ & 10.050551 & $10 \_483.115$ & $10 \_087 \_068$ \\
\hline $5-9$ & $10.626-440$ & 102661.848 & $10 \_546.791$ & $10 \_182 \_779$ & $10 \_467.737$ & $10 \_104317$ \\
\hline 10-14 & 10339940 & 9.982 .913 & 10268 265 & 9919_815 & 10_197_085 & 9.857_115 \\
\hline $15-19$ & $10.863 \_403$ & 10.6482277 & $10906-322$ & 10.661 .732 & $10 \_949.412$ & 10.6752204 \\
\hline $20-24$ & 10272910 & 10298.880 & $103667 \_569$ & 10299510 & $10 \_463 \_098$ & $10300 \_140$ \\
\hline $25-29$ & 9.885 .713 & $10 \_097535$ & 10.022380 & 10.189320 & $10 \_160933$ & 102881937 \\
\hline $30-34$ & 9_087_048 & 9_458_197 & 9201.822 & 9.631 .960 & 9318_043 & 9.808.909 \\
\hline $35-39$ & $8330 \ldots 783$ & 8_565_677 & 8.4755288 & 8_771_135 & 8.622 .783 & 8981513 \\
\hline $40-44$ & $7 \_466 \_491$ & 7.352 .547 & 7.646 .187 & $7580 \_049$ & $7.830 \_201$ & 7.8145850 \\
\hline $45-49$ & 6314.857 & 6_065_499 & 65332384 & 6334.298 & 6.757394 & 6.614.994 \\
\hline $50-54$ & 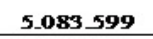 & 4_831_618 & $5320 \ldots 185$ & 5_070_805 & 5567.770 & 5321820 \\
\hline $55-59$ & 3913263 & 3_729_429 & 4_093_408 & 3.881_587 & 4.281_840 & 4_039948 \\
\hline $60-64$ & 2956293 & 2.974_869 & 3_045_274 & 3_045_218 & 3_136931 & 3.117230 \\
\hline $65-69$ & $2120-724$ & 2.286200 & 2.178330 & 2.336 .352 & $2.237 \_499$ & $2.387 \_603$ \\
\hline $70-74$ & $1515 \_894$ & $1.713 \_691$ & 1562342 & 1.774 .685 & 1.610213 & 1.837 .849 \\
\hline $75+$ & 1557313 & 1.9995568 & 15911611 & 2_049_500 & 1.626_663 & 2.100 .678 \\
\hline Total & 110.734369 & 110280.913 & 112.199 .721 & 111.779295 & 113.710 .718 & 113330.907 \\
\hline
\end{tabular}

\begin{tabular}{|c|c|c|c|c|c|c|}
\hline \multirow[t]{2}{*}{ Kelompole Umm } & \multicolumn{2}{|l|}{2009} & \multicolumn{2}{|l|}{2010} & \multicolumn{2}{|l|}{2011} \\
\hline & Laki-1aki & Perempnan & Lalai-1alai & Perempuan & Lalai-1aki & Perempanan \\
\hline $0-4$ & $10 \_525 \_074$ & 10_123_718 & 10567200 & 10_160_500 & 10_609_495 & 10_197_416 \\
\hline $5-9$ & 10389275 & $10 \_026.459$ & 10311.400 & 9_949_200 & 102344107 & 9.872 .535 \\
\hline 10-14 & 10.126398 & 9.794.811 & 10.0562200 & 9.732 .900 & 99886_488 & 9.671380 \\
\hline 15-19 & 109992.671 & 10_688_694 & 11.036 100 & 10.702200 & 11_079_701 & 10.715_723 \\
\hline $20-24$ & 10559506 & $10300 \_770$ & 10.656 .800 & 10301 .400 & 10.754989 & 10302.030 \\
\hline $25-29$ & 10301398 & 10375395 & 10_443_800 & $10 \_469 \_700$ & 10_588_167 & 10.564 .861 \\
\hline $30-34$ & $9.435 \_730$ & 9989_103 & 9554900 & $10 \_172 \_600$ & 9.675572 & 10359.461 \\
\hline $35-39$ & 8.772.592 & 9.196928 & 8925_000 & 9_417_500 & 9_080_0s1 & 9.643 .352 \\
\hline $40-44$ & 8_018_637 & 8.056356 & 8211_600 & 8_305_600 & 8_409_199 & 8.562 .542 \\
\hline $45-49$ & 6.990_144 & 6908.112 & 7230900 & 7.214 .200 & 7.479936 & 7533.831 \\
\hline $50-54$ & 5.826.864 & 5.585248 & 6.098_000 & 5.861 .700 & 6381.737 & 6.151 .820 \\
\hline $55-59$ & 4_478.938 & 4.204.765 & 4.685_100 & 4.376_300 & 4900_743 & 4.554 .827 \\
\hline $60-64$ & 32331346 & 3_190_944 & 3328.600 & $3 \_266-400$ & $3 \_428.779$ & 3343.639 \\
\hline $65-69$ & $2.298 \quad 274$ & 2439977 & 2360.700 & $2.493 \_500$ & 2.424 .820 & 2548.196 \\
\hline $70-74$ & 1.6595551 & 1.903261 & 1.710_400 & 1.971_000 & 1.762_806 & 2.041149 \\
\hline $75+$ & 1_662_487 & 2153_135 & 1.699_100 & 2.206_900 & 1.7365519 & 2262.007 \\
\hline Total & 115268.884 & $1149937 \_674$ & 116_875_800 & 116_601_600 & 118_533_109 & 118324769 \\
\hline
\end{tabular}

5. Perbandingan Model Malthus dan Model Verhulst untuk Estimasi Jumlah Penduduk

Dari hasil estimasi jumlah penduduk Indonesia berdasarkan kelompok umur tahun 2000 - 2014 dengan model Malthus dan model Verhulst, maka akan dipilih model 
Tabel 7. Estimasi Jumlah Penduduk Indonesia Berdasarkan Jenis Kelamin dan Kelompok Umur dengan Model Verhulst (lanjutan)

\begin{tabular}{|c|c|c|c|c|c|c|}
\hline \multirow[t]{2}{*}{ Kelomipok Uninur } & \multicolumn{2}{|l|}{2012} & \multicolumn{2}{|l|}{2013} & \multicolumn{2}{|l|}{2014} \\
\hline & Laki-laki & Perempuan & Laki-laki & Perempuan & Laki-laki & Perempuan \\
\hline $0-4$ & 10.651 .958 & 10.234 .465 & 10.694 .591 & 10271649 & 10.737394 & 10308968 \\
\hline $5-9$ & 10.157393 & 9.796 .459 & 10.081253 & 9720969 & 10.005 .682 & $9.646 \_059$ \\
\hline $10-14$ & 9917258 & 9.610 .247 & 9.848507 & 9549501 & 9.780231 & $9.489 \_137$ \\
\hline 15-19 & 11 123_473 & 10729264 & 11167.418 & 10742821 & 11211537 & 10.756396 \\
\hline $20-24$ & 10.854 .030 & 10302660 & 10954.083 & 10303291 & $11055 \_004$ & 10303921 \\
\hline $25-29$ & 10.734525 & 10.660 .884 & 10.882902 & 10757.779 & 11033326 & 10.855553 \\
\hline $30-34$ & 9.797_766 & $10 \_549.748$ & 9921500 & 10743523 & 10.046 .793 & 10.940 .849 \\
\hline $35-39$ & 92377790 & 9.874 .610 & 9398265 & 10111403 & $9 \longdiv { 6 1 5 2 2 }$ & 10353.863 \\
\hline $40-44$ & 8.611545 & 8.827_420 & 8.818752 & $9.100-477$ & 9.030936 & 9381965 \\
\hline $45-49$ & 7.737536 & $7.867 / 601$ & 8003994 & 8216.135 & 8.279.612 & 8_580_083 \\
\hline $50-54$ & 6.678_659 & 6.456 .280 & 6989378 & 6775789 & 7314531 & 7_111_ogs \\
\hline $55-59$ & 5.126301 & 4.740.629 & 5362230 & 4.934_004 & 5.609 .006 & 5.135259 \\
\hline $60-64$ & 3531972 & 3.422703 & 3.638267 & $3 \lcm{503.636}$ & 3.747 .760 & 3_586_481 \\
\hline $65-69$ & $2.490 \_682$ & 2604.092 & 2558331 & 2661213 & 2.627 .817 & 2719586 \\
\hline $70-74$ & 1.816.818 & 2113.793 & 1872484 & 2189.022 & 1929.854 & 2266927 \\
\hline $75+$ & 1.774 .762 & 2318.490 & 1813.846 & 2376383 & 1.853.791 & $24435-720$ \\
\hline Total & 120242518 & $120 \_109348$ & 122005.900 & 121957.595 & 123.824 .797 & 123.871856 \\
\hline
\end{tabular}

terbaik dengan menentukan $\bar{\varepsilon}$ (rata-rata galat mutlak) yang terkecil, yaitu::

$$
\bar{\varepsilon}=\frac{\sum_{t=0}^{N-1}|p \hat{(t)}-p(t)|}{N} .
$$

Diperoleh $\bar{\varepsilon}$ untuk masing-masing model jumlah penduduk Indonesia, sebagai berikut.

Pada Tabel 8 terlihat rata-rata galat untuk penduduk laki-laki dengan menggunakan model Malthus yaitu 526.184,1 lebih besar daripada menggunakan model Verhulst yaitu 415.414,4 dan penduduk perempuan dengan menggunakan model Malthus yaitu 492.291,2 lebih besar daripada menggunakan model Verhulst yaitu 491.646,5. Dengan demikian, baik untuk hasil estimasi jumlah penduduk laki-laki maupun perempuan dengan menggunakan model Verhulst memiliki nilai rata-rata galat $(\bar{\varepsilon})$ lebih kecil daripada menggunakan model Malthus. Oleh karena itu, data hasil estimasi jumlah penduduk Indonesia tahun 2000-2014 yang menggunakan model Verhulst (model logistik) lebih mendekati dengan data hasil estimasi jumlah penduduk Indonesia tahun 2000 - 2014 yang dilakukan oleh BPS.

Dalam Gambar 1 dan Gambar 2 diberikan grafik perbandingan hasil estimasi jumlah penduduk Indonesia tahun $2000-2014$.

\section{Kesimpulan}

Berdasarkan hasil pembahasan estimasi jumlah penduduk menggunakan model Malthus (model eksponensial) dan model Verhulst (model logistik) dengan menghi- 
Tabel 8. Hasil $\bar{\varepsilon}$ Model-model Pertumbuhan Penduduk

\begin{tabular}{|c|c|c|c|c|c|c|}
\hline \multirow{3}{*}{ Tahmn } & \multirow{2}{*}{\multicolumn{2}{|c|}{ Hasil Estimasi BPS }} & \multicolumn{4}{|c|}{$\boldsymbol{\varepsilon}$} \\
\hline & & & \multicolumn{2}{|c|}{ Model Malfhns } & \multicolumn{2}{|c|}{ Model Verhnlts } \\
\hline & Laki-laki & Perempuan & Laki-laki & Perempuan & Laki-laki & Perempuan \\
\hline 2000 & 102.822 .400 & 102.309 .600 & $\mathbf{0}$ & $\mathbf{O}$ & $\mathbf{0}$ & $\mathbf{0}$ \\
\hline 2001 & 104.196.000 & 103.731 .500 & 1 .298_098 & 206.624 & 153.163 & 206.416 \\
\hline 2002 & 105.584 .300 & 105.152 .000 & 753.539 & 368.681 & 283.403 & 368.296 \\
\hline 2003 & 106.982 .000 & 106.568 .500 & 268.965 & 482.044 & 384.205 & 481.517 \\
\hline 2004 & 108.392 .000 & 107.989 .600 & 160.492 & 553.727 & 457.208 & 553.097 \\
\hline 2005 & 109.801 .700 & 109.403 .000 & 523.824 & 569.775 & 488.504 & 569.091 \\
\hline 2006 & 111.208 .500 & 110.842 .800 & 664.974 & 562.573 & 474.131 & 561.887 \\
\hline 2007 & 112.627 .100 & 112.277 .800 & 773.560 & 499.132 & 427.379 & 498.505 \\
\hline 2008 & 114.051 .100 & 113.728 .000 & 841.748 & 397.593 & 340.382 & 397.093 \\
\hline 2009 & 115.458 .700 & 115.174 .000 & 846.244 & 236.620 & 189.816 & 236.326 \\
\hline 2010 & 116.875 .800 & 116.601 .600 & $\mathbf{o}$ & $\mathbf{o}$ & $\mathbf{O}$ & $\mathbf{o}$ \\
\hline 2011 & 118.287 .500 & 118.043 .800 & 720.688 & 281.362 & 245.609 & 280.969 \\
\hline 2012 & 119.698 .900 & 119.475 .400 & 577.542 & 634.848 & 543.618 & 633.948 \\
\hline 2013 & 121.100 .500 & 120.913 .300 & 370.710 & 1.045 .827 & 905.300 & 1.044 .295 \\
\hline 2014 & 122.486 .300 & 122.328 .600 & 92.377 & 1.545 .562 & 1.338 .497 & 1.543 .257 \\
\hline \multicolumn{3}{|c|}{$\bar{E}$} & $526.184,1$ & $492.291,2$ & $415.414,4$ & $491.646,5$ \\
\hline
\end{tabular}

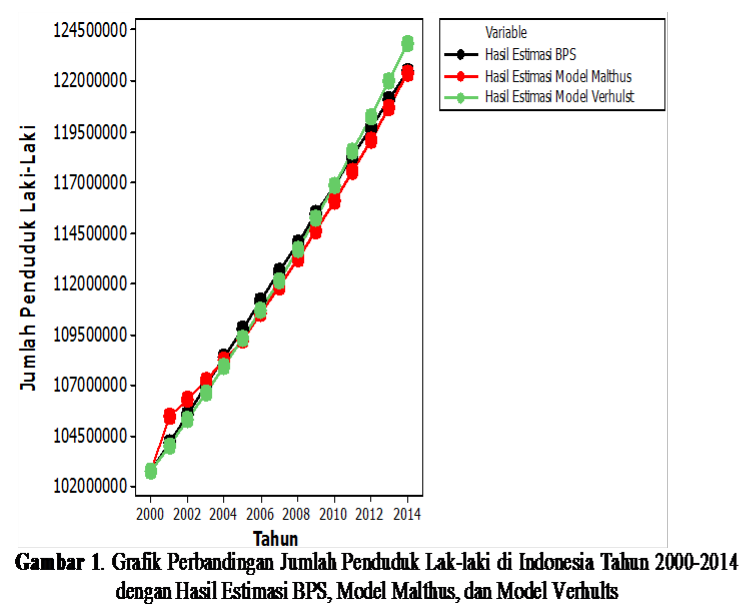
dengan Hasil Estimasi BPS, Model Malthus, dan Model Vehtults

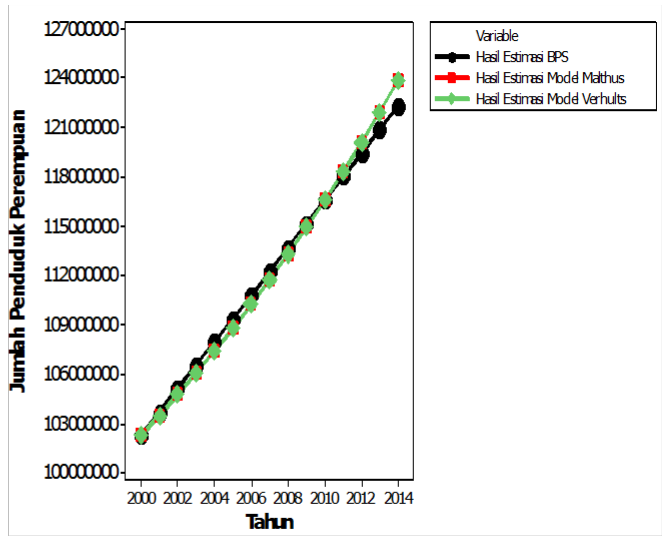

Gabbar 2. Grafik Perbandingan Jumlah Penduduk Lak-laki di Indonesia Tahun 2000-2014 dengan Hasil Estimasi BPS, Model Malthus, dan Model Verhults

tung rata-rata galat $(\bar{\varepsilon})$ dari masing-masing model, dapat disimpulkan bahwa model untuk menentukan hasil estimasi jumlah penduduk Indonesia tahun 2000-2014 berdasarkan jenis kelamin dan kelompok umur yang lebih mendekati dengan hasil sensus dan hasil estimasi yang dilakukan oleh Badan Pusat Statistik (BPS) adalah model Verhulst (model logistik). 


\section{Daftar Pustaka}

[1] Adioetomo, S. Moertiningsih dan O.B. Samosir. 2010. Dasar-dasar Demografi. Lembaga Demografi Fakultas Ekonomi Universitas Indonesia, Salemba Empat, Jakarta

[2] Badan Pusat Statistika (BPS), BAPPENAS, dan UNFPA. 2005. Proyeksi Penduduk Indonesia (Indonesia Population Projection). Jakarta

[3] Finizio, N. dan G. Ladas. 1988. Persamaan Diferensial Biasa dengan Penerapan Modern. Alih bahasa Widiarti, Edisi ke-2. Jakarta: Erlangga. 